\title{
U NHẦY TÂM THẤT PHẢI: NHÂN MộT TRƯờNG HợP
}

\section{Đỗ Kim Quế}

\section{Tóm tắt:}

U nhầy tim là loại u tim thường gặp nhất, đa số

\section{* Bệnh viện Thống Nhất Thành phố HCM}

các trường hợp u nằm tại tâm nhĩ. U nhầy tâm thất rất hiếm gặp. Chúng tôi trình bày một trường hợp u nhầy tâm thất phải được chẩn đoán và điều trị phẫu thuật thành công tại bệnh viện Thống nhất. Bệnh nhân nữ 47 tuổi nhập viện vì mệt khó thở. Siêu âm tim qua thành ngực phát hiện u trong buồng tống thất phải di chuyển lên xuống động mạch phổi. Bệnh nhân được phẫu thuật lấy $\mathrm{u}$ qua đường mở động mạch phổi và đường mở nhĩ phải với tuần hoàn ngoài cơ thể. Khối u có cuống xuất phát từ cột cơ lá van ngoài van 3 lá và thành trước thất phải. Hậu phẫu ổn định, xuất viện sau 10 ngày. Kết quả giải phẫu bệnh khối u là myxoma lành tính. Theo dõi sau 5 năm chưa thấy dấu hiệu tái phát.

\section{SUMARY: RIGHT VENTRICULAR MYXOMA. A CASE REPORT}

The Author present a case with right ventricular myxoma who was operated successfully. A female 47 year old admited with fatigue and dyspnea. TEE determined a big mass in right ventricle. The urgent operation were done to remove the tumor with CPB. The pedicle of myxoma locate at the papilla of the tricuspid valve and the anterior of the right ventricle. Pathologic result is benign myxoma. The patient is in good condition till 5 year follow - up, no evidence of recurrence.

Tù khóa: u nhầy, u nhầy tâm thất phải.

\section{I - MỞ Đî̀̂U:}

U cơ tim là một bệnh lý hiếm gặp, theo y văn tỉ lệ u tim được phát hiện trên tử thiết thay đổi từ $0.0017-0.19 \%^{[10]}$. Tuỳ thuộc vị trí khối u trong tim mà có biểu hiện lâm sàng khác nhau. Đa số các trường hợp $\mathrm{u}$ trong tim được phát hiện với các triệu chứng không đặc hiệu như mệt mỏi, sụt cân, thiếu máu .. ${ }^{[5,6,9]}$
U nhầy tim là loại u tim thường gặp nhất, Goldberg lần đầu tiên phát hiện u nhầy trong tim bằng $X$ quang buồng tim năm 1951. Bahnson và Newman đã tiến hành phẫu thuật cắt u nhầy nhĩ phải qua đường mở ngực vào năm 1952, tuy nhiên bệnh nhân tử vong sau 24 ngày. Năm 1954 trường hợp u nhầy nhĩ $\mathrm{T}$ đầu tiên được phẫu thuật thành công với máy tuần hoàn ngoài cơ thể bởi Crawfoord. ${ }^{[9,10]}$

Đa số các trường hợp u nhầy trong tim nằm ở nhĩ trái , những trường hợp u nhầy trong tâm thất rất hiếm gặp. Vừa qua tại bệnh viện Thống nhất chúng tôi đã điều trị phẫu thuật thành công một trường hợp u nhầy trong tâm thất phải có cuống từ cột cơ van 3 lá. Đây là một trường hợp rất hiếm gặp, chúng tôi trình bày kinh nghiệm trong chẩn đoán và xử trí cho bệnh lý hiếm gặp này.

\section{II - BỆNH ÁN:}

Bệnh nhân Phan Thị N. nữ, 47 tuổi nhập bệnh viện Thống Nhất lúc 16h ngày 30/06/2005 vì mệt mỏi và khó thở. Số nhập viện: 64479

\section{Bênh sử:}

Cách nhập viện 1 tháng bệnh nhân thấy mệt mỏi, khó thở khi gắng sức. 1 tuần trước nhập viện bệnh nhân thấy mệt nhiều hơn, đôi khi chóng mặt muốn ngất xỉu ngay cả khi nghỉ ngơi. Ngày nhập viện bệnh nhân thấy mệt nhiều khó thở liên tục, nặng ngực trái nên được đưa vào bệnh viện Thống Nhất.

Tînh trang khi nhập viện:

Tỉnh táo, khó thở vừa, mạch: 85 lần/phút, huyết áp: 85/50 mmHg, nặng: 52 kg, cao $1 \mathrm{~m} 55$.

NYHA 3, Phổi rì rào phế nang 2 bên đều, không rale.

Tim đều, âm thổi tâm thu 3/6 liên sườn II bờ trái xương ức, và liên sườn IV bờ trái ức.

Bụng mềm, gan lách không lớn. Hồng cầu 4.23

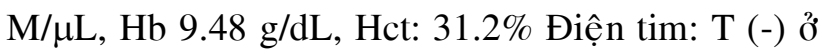
$\mathrm{V} 1-\mathrm{V} 4$ 


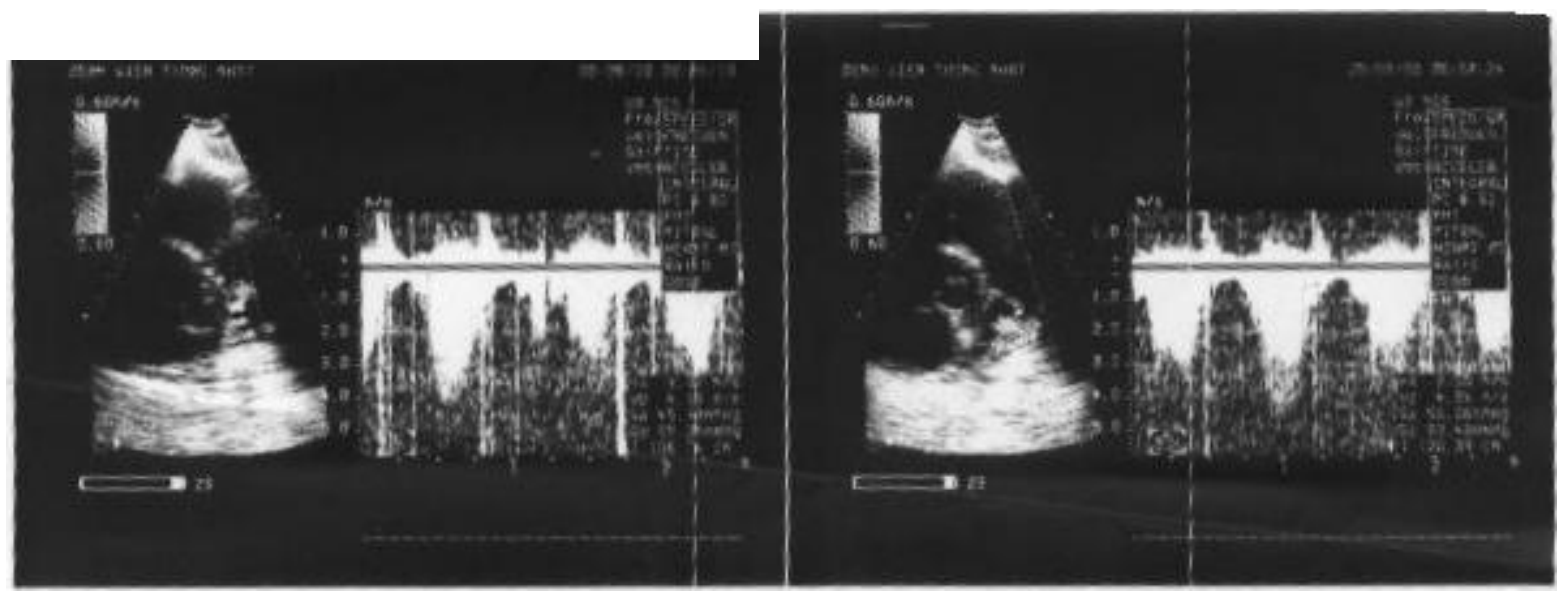

Hình 1: Siêu âm tim qua thành ngực

Echo tim qua thành ngực và qua thực quản: Ghi nhận khối u trong buồng thất phải di chuyển lên xuống vào động mạch phổi theo chu chuyển tim, nghi ngờ u có cuống từ vách liên thất nhưng đã đứt cuống.

Bệnh nhân được chẩn đoán u nhầy tâm thất phải và chỉ định phẫu thuật cắt $\mathrm{u}$.

\section{Tường trình phẫu thuât:}

Mở ngực dọc giữa xương ức, chạy máy tuần hoàn ngoài cơ thể với cannula động mạch chủ lên và 2 cannula tĩnh mạch.
Kẹp động mạch chủ, làm liệt tim với dung dịch liệt tim máu ấm. Tim ngừng tốt, mở động mạch phổi, qua lỗ van động mạch phổi thấy khối u trong hồng nhiều thùy trong buồng tâm thất phải. Mở nhĩ phải không thấy u trong buồng nhĩ, toàn bộ u nằm trong buồng thất phải với kích thước 4 × 3 x 6 $\mathrm{cm}$.

Lấy khối u khá khó khăn qua chỗ mở động mạch phổi. Kiểm tra thấy khối u xuất phát từ cột cơ của lá van ngoài van 3 lá. Cắt phần cột cơ có khối u.

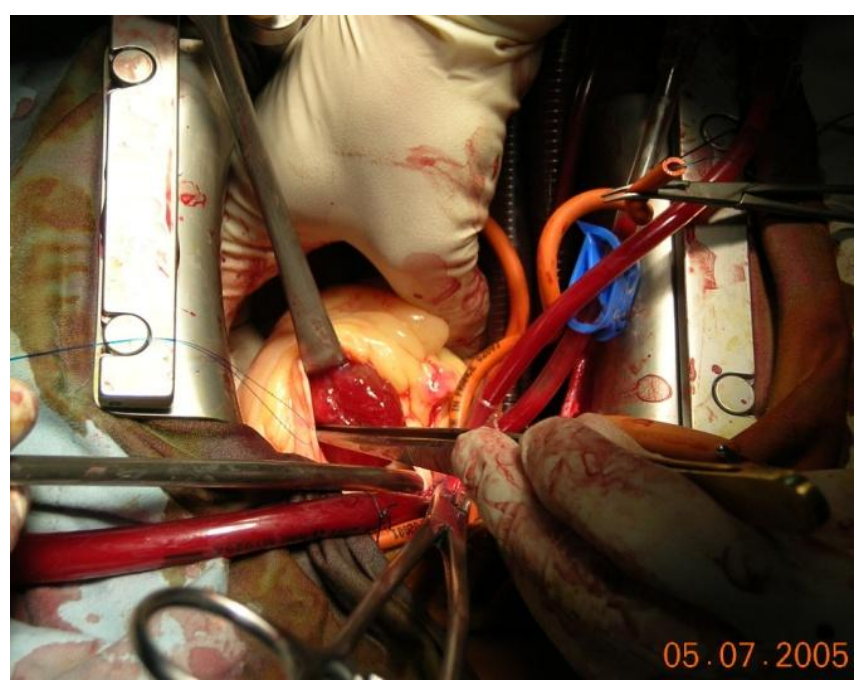

Hình 2: Khối u nhầy trong buồng thất phải 
Đóng lại động mạch phổi và nhĩ phải. Thời gian kẹp động mạch chủ 55 phút, chạy máy tuần hoàn ngoài cơ thể 92 phút.

Hậu phẫu diễn biến thuận lợi, bệnh nhân xuất viện sau 10 ngày trong tình trạng ổn định.

\section{III - BÀN LUẬN :}

U cơ tim là một bệnh lý khá hiếm gặp, nhiều trường hợp chẩn đoán khó và không được xử trí cho tới khi có biến chứng.

Đa số các trường hợp u tim thuộc u lành tính, trong đó u nhầy là loại thường gặp nhất, theo báo cáo

Bảng 1: Tần suất u tim ( Theo McAllister và cs.) ${ }^{[12]}$

\begin{tabular}{lll}
\hline Loại & Số truờng hơp & \% \\
\hline U lành & $\mathbf{4 0 8}$ & $\mathbf{7 6 . 5}$ \\
Myxoma & 130 & 24.4 \\
Lipoma & 45 & 8.4 \\
Papillary fibroelastoma & 42 & 7.9 \\
Rhabdomyoma & 36 & 6.8 \\
Fibroma & 17 & 3.2 \\
Hemangioma & 15 & 2.8 \\
Teratoma & 14 & 2.6 \\
Mesothelioma nút nhĩ thất & 12 & 2.3 \\
U tế bào hạt & 3 & 0.6 \\
U sợi thần kinh & 3 & 0.6 \\
Lymphangioma & 2 & 0.4 \\
U nang màng ngoài tim & 82 & 15.4 \\
U nang phế quản & 7 & 1.3 \\
Ac tính & $\mathbf{1 2 5}$ & $\mathbf{2 3 . 5}$ \\
Angiosarcoma & 39 & 7.3 \\
Rhabdomyosarcoma & 26 & 4.9 \\
Mesothelioma & 19 & 3.6 \\
Fibrosarcoma & 14 & 2.6 \\
Lymphoma & 7 & 1.3 \\
Osteosarcoma ngoài xương & 5 & \\
Neurologic sarcoma & 4 & \\
Teratoma ác tính & 4 & \\
Thymoma & 1 & \\
Leiomyosarcoma & 1 & \\
Liposarcoma & 1 & \\
Synovial sarcoma & 1 & \\
\hline
\end{tabular}

Trong thời gian 34 năm tại Mayo clinic đã phẫu thuật cho 80 trường hợp u nhầy trong tim.[11] Tại Viện tim TP. Hồ Chí Minh trong 6 năm từ 1992 - 1998 đã gặp 32 trường hợp u nhầy trong tim. ${ }^{[15]}$ Theo Nguyễn Hữu Thịnh và cs. ${ }^{[13]}$ trong 2 năm từ 2000 - 2002 tại bệnh viện Chợ rẫy có điều trị cho 7 trường hợp u nhầy trong tim. 
Vị trí u nhầy thường gặp nhất là ở nhĩ trái với tỉ lệ từ 75 - 90\% các trường hợp. Trong số 32 trường hợp u nhầy tim của Viện tim TP. Hồ Chí Minh có 29 trường hợp u nhầy nhĩ trái. Theo Schaff và cs. trong 80 trường hợp u nhầy tim tại Mayo clinic thì $80 \%$ các trường hợp u nằm trong nhĩ trái. ${ }^{[2,14,16]}$

U nhầy trong tâm thất là khối u rất hiếm gặp chiếm tỉ lệ $2-4 \%$ các trường hợp u nhầy tim. Theo Mc Alister có 5 trường hợp u nhầy trong thất phải trong 130 trường hợp u nhầy trong tim.

Bảng 2: Vị trí u nhầy tim

\begin{tabular}{lllll}
\hline Tác giả & Nhĩ trái & Nhĩ phải & Thất trái & Thất phải \\
\hline McAllister & $97(74.7 \%)$ & $23(17.7 \%)$ & $5(3.8 \%)$ & $5(3.8 \%)$ \\
Phạm Nguyễn Vinh & $29(90.6 \%)$ & $3(9.4 \%)$ & 0 & 0 \\
Schaff HV & $64(80 \%)$ & $16(20 \%)$ & 0 & 0 \\
Nguyễn Hữu Thịnh & $6(82.5 \%)$ & $1(17.5 \%)$ & 0 & 0 \\
Kiklin JW, Barratt Boyes & $31(79.5 \%)$ & $7(17.9 \%)$ & $1(2.6 \%)$ & 0 \\
\hline
\end{tabular}

Trường hợp u nhầy tâm thất phải chúng tôi gặp là 1 trường hợp rất hiếm gặp khi vị trí xuất phát khối u từ cột cơ của van 3 lá. Trong y văn chúng tôi tìm được có 2 trường hợp đã được Suri RK công bố. ${ }^{[18]}$ Tại Việt nam chúng tôi chưa ghi nhận báo cáo nào về u nhầy trong tâm thất.

U nhầy trong tim thường gặp ở phụ nữ tuổi trung niên, đa số các nghiên cứu cho thấy tỉ lệ nữ:nam từ $4-9$ lần. Mặc dù u nhầy có thể gặp ở mọi độ tuổi nhưng lứa tuổi thường gặp nhất là $30-60$ tuổi. Theo Schaff ${ }^{[16]}$ tuổi trung bình của 80 bệnh nhân u nhầy trong tim tại Mayo clinic là 53; Tất cả các trường hợp u nhầy tim tại bệnh viện Chợ rẫy đều trên 20 tuổi, Tại Viện tim TP. Hồ Chí Minh chỉ có 1 trường hợp bệnh nhi 11 tháng tuổi.

Bệnh nhân u nhầy tâm thất phải chúng tôi gặp cũng nằm trong độ tuổi thường gặp của bệnh lý này.

Về các dấu hiệu lâm sàng của u nhầy trong tim đa phần không đặc hiệu, theo y văn $90 \%$ các trường hợp u nhầy trong tim nhập viện vì các triệu chứng toàn thân không đặc hiệu như mệt mỏi, sụt cân, thiếu máu, sốt âm ỉ. Số bệnh nhân còn lại nhập viện với các triệu chứng do khối u nhầy gây cản trở sự lưu thông máu trong tim hoặc do u nhầy bong ra gây nghẽn động mạch. ${ }^{[3,7,11]}$

Trường hợp u nhầy trong tâm nhĩ trái thường gây cản trở máu về thất trái gây các triệu chứng lâm sàng tương tự như những trường hợp hẹp van hai lá với khó thở, khám tim có tiếng rung tâm trương, tuy nhiên triệu chứng này thay đổi theo tư thế.

U nhầy trong nhĩ phải thường gây u máu ở nhĩ phải và tĩnh mạch ngoại biên với dấu hiệu tĩnh mạch cổ nổi, gan to ứ huyết, tuy nhiên các triệu chứng này thay đổi nhanh.

U nhầy trong tâm thất khó chẩn đoán hơn và ít khi phát hiện triệu chứng đặc hiệu.

Bệnh nhân của chúng tôi nhập viện với các triệu chứng không đặc hiệu, khám lâm sàng phát hiện tiến thổi tâm thu vùng van 2 lá và van động mạch phổi.

Chẩn đoán u nhầy trong tim thường chỉ được xác định trên siêu âm tim. Ngày nay với siêu âm tim qua thực quản cho phép chẩn đoán chính xác kích thước, vị trí xuất phát của u nhầy. ${ }^{[1,8]}$ Tuy nhiên những trường hợp u quá lớn thường việc xác định chính xác vị trí cuống khối u đôi khi gặp nhiều khó khăn. Trường hợp u nhầy chúng tôi gặp có kích thước rất lớn $3 * 6 * 4 \mathrm{~cm}$ và chiếm gần hết buồng thất phải.

CT scan và MRI là những phương pháp chẩn đoán hình ảnh khác rất có giá trị trong chẩn đoán u nhầy tim.

Về điều trị u nhầy tim chỉ có phương pháp phẫu thuật là cách điều trị hiệu quả và triệt để. Phẫu thuật cắt u nhầy với tuần hoàn ngoài cơ thể cho phép cắt toàn bộ u nhầy. Đây là phương pháp điều trị khá an toàn với tỉ lệ tử vong thấp khoảng $3-5 \%$. ${ }^{[4,9,14,16]}$

Với u nhầy trong nhĩ đường vào tim thường được chọn là đường qua 2 nhĩ và vách liên nhĩ. Khối u được cắt bỏ cùng cuống khối $\mathrm{u}$ - đa số nằm ở vách liên nhĩ. Phần thành tim bị cắt bỏ được phục hồi với màng ngoài tim tự thân hoặc miếng ghép mạch máu.

U nhầy trong thất phải có thể được cắt bỏ qua đường mở thất hoặc mở động mạch phổi và đường mổ nhĩ phải. Chúng tôi chọn lựa đường mở động mạch phổi phối hợp với đường mở nhĩ phải để hạn chế biến 
chứng loạn nhịp sau mổ. Tuy nhiên đường mổ này gây khó khăn do trường mổ hẹp hơn. Khối u đã được cắt bỏ từng phần và cuống tại thành trước thất phải và cột cơ của lá ngoài van ba lá được cắt bỏ toàn bộ sau đó.

Nguy cơ tái phát của u nhầy tim khá thấp khoảng 1$3 \%$ và đa số xuất hiện trong 48 tháng. ${ }^{[5,6,9]}$ Trường hợp của chúng tôi đã theo dõi 36 tháng chưa thấy dấu tái phát.

\section{IV - KẾT LUẬN}

U nhầy tâm thất là một bệnh hiếm gặp đặc biệt khi u xuất phát từ cột cơ van 3 lá. Chẩn đoán được xác định qua siêu âm tim. Phẫu thuật cắt bỏ khối u với máy tuần hoàn ngoài cơ thể là phương pháp điều trị triệt để và cho kết quả khả quan.

Trường hợp được báo cáo là một thành công của bệnh viện trong chẩn đoán và xử trí một bệnh lý hiếm gặp. Bệnh nhân cần tiếp tục được theo dõi để phát hiện sớm tái phát.

\section{TÀI LIỆU THAM KHẢO:}

1. Borges AC, Witt C, Bartel T, Muller S, Konerzt W, Baumann G.: Preoperative two - and three dimentional transesophageal echocardiographic assessment of heart tumors. Ann Thorac Surg. 1996, 61(4): 1163 -1167.

2. Edo A, Ohtahara A, Kinugawa T, Nawada T, Fujimoto Y, Shigemasa C.: Clinical incidence of primary cardiac tumors. J Cardiol. 1996, 28(4): $227-234$.

3. Floriani $\mathrm{M}$, Canini $\mathrm{T}$, Padalino $\mathrm{P}$, Bordoni $\mathrm{P}$, Tiberio G.: Simultaneous multiregional embolization from a cardiac myxoma. A case report. Ann Ital Chir, 1995, 66(6): 887-891.

4. Greco E, Mestres CA, Cartana R, Polmar JL.: Video assisted cardioscopy for removal of primary left ventricular myxoma. Eur $\mathrm{J}$ Cardiothorac Surg. 1999, 16(6): 677-678.

5. Hall RJ, Cooley DA, McAllister HA, Frazier OH. : Neoplastic heart disease. In the heart arteries and veins. $8^{\text {th }}$ Ed. McGraw Hill Inc 1994. p. 2007 $-2024$

6. Hall RJ, Cooley DA, McAllister HA, Buja LM. : Tumors of the heart. In Cardiovascular medicine. Churchill Livingstone Inc. 1995. p. 1525 - 1535.
7. Hayashi S, Takahashi H, Shimura T, Nakazawa S. : A case of multiple cerebral aneurysm which showed rapid growth cause by left atrial myxoma. No-Shinkei-geka, 1995, 23(11) : 977980.

8. Kazakis D, Lewis JF, Conti CR.: Transesophageal echocardiography in the evaluation of cardiac myxoma: A case of familial myxoma. Clin Cardiol. 1995, 18(5): 283-285.

9. Kirklin JW, Barratt-Boyes BG.: Cardiac tumor. In Cardiac surgery. Churchill Livingstone Inc. 1993. p. $1635-1653$.

10. Majano Lainez RA.: Cardiac tumor: A current clinical and pathological perspective. Crit Rev Onco. 1997, 8(4): 293 - 303.

11. Markel ML, Waller BF, Armstrong WF.: Cardiac myxoma. A review. Medicine baltimore, 1987, 66(2): $114-125$.

12. McAllister HA, Fenoglio JJ. : Tumors of the cardiovascular system. Washinton, DC Armed Force Institute of pathology, 1978.

13. Nguyễn Hữu Thịnh, Lý Thụy Đoan Trinh, Nguyễn Thị Hậu, Đỗ Kim Quế và Cs. (2002): Báo cáo về các trường hợp u nhầy tim đã được phẫu thuật tại bệnh viện Chợ rẫy từ 01/03/2000 đến 01/08/2002. Y học TP. Hồ Chí Minh. 3:597602.

14. Perchinsky MJ, Lichtenstein SV, Tyers GF.: Primary cardiac tumors: forty years' experience with 71 patients. Cancer, 1997 79(9): 1809-1815.

15. Phạm Nguyễn Vinh, Phan Kim Phương: U nhầy tim - Đặc điểm lâm sàng một số vấn đề về chẩn đoán và điều trị. Tổng kết u nhầy tim từ 1992 1998

16. Selvaraj A, Kumar R, Ravikumar E.: Surgical management of right atrial myxomas. A15 year experience with review of the literature. J Cardiovasc Surg. 1999, 40(1): 101-105.

17. Schaff HV, Lie JT, Giullani ER.: tumors of the heart. In Mayo clinic practice of cardiology. Mosby $3^{\text {rd }}$ Ed. p. 1648 - 1726. Suri RK, Pattankar VL, Shingh H, Aikat BK, Gujral JS.: Myxoma of the tricuspid valve. Aust NZ J Surg 1978, 48: 428-429. 